\title{
Perceptions of the food shopping environment are associated with greater consumption of fruits and vegetables
}

\author{
Jonathan L Blitstein ${ }^{1, *}$, Jeremy Snider ${ }^{2}$ and W Douglas Evans ${ }^{2}$ \\ ${ }^{1}$ RTI International, 3040 East Cornwallis Road, Research Triangle Park, NC 27709-2194, USA: ${ }^{2}$ The George \\ Washington University, School of Public Health and Health Services, Washington, DC, USA
}

Submitted 27 June 2011: Accepted 17 January 2012: First published online 21 February 2012

\begin{abstract}
Objective: The present study examined whether characteristics such as quality, selection and convenience are associated with dietary intake of fruits and vegetables independent of perceived costs in an inner-city, low-income population.

Design: Secondary analysis of baseline data from a social marketing intervention designed to change household dietary practices among parents of 3- to 7-year-old children.

Setting: A community sample drawn from six low-income, primarily minority neighbourhoods in Chicago, IL, USA.

Subjects: From the parent study, 526 respondents completed the baseline survey and were eligible for inclusion. Of this number, 495 provided complete data on sociodemographic characteristics, fruit and vegetable consumption, perceptions of the shopping environment, perceived costs of fruits and vegetables, and food shopping habits.

Results: Logistic regression analysis showed that more positive perceptions of the food shopping environment were associated with greater consumption of fruits and vegetables. There was an increase of approximately twofold in the likelihood of consuming three or more fruits and vegetables daily per level of satisfaction ascribed to the shopping environment. This association was independent of perceived cost, store type and sociodemographic characteristics.

Conclusions: Our data show that among a generally minority and low-income population, quality, selection and convenience are important determinants of fruit and vegetable consumption. Nutrition promotion campaigns that aim to alter the built environment by increasing access to fruits and vegetables should recognize that simply increasing availability may not yield beneficial change when characteristics of the shopping context are ignored.
\end{abstract}

\author{
Keywords \\ Retail food environment \\ Store characteristics \\ Fresh fruits and vegetables
}

Current recommendations in the USA call for increasing the proportion of fruits and vegetables in the daily diet as a way to meet nutritional needs while maintaining energy balance ${ }^{(1)}$. Fruits and vegetables have a high water content and low energy density which can lead to feelings of satiety that reduce energy intake, a key factor in preventing weight gain ${ }^{(2)}$. Additionally, diets high in fruits and vegetables are lower in saturated fat and total fat, and have been associated with reduced risks of CVD and many site-specific cancers ${ }^{(3)}$

Achieving these goals may be easier for some than for others. Socio-economic status (SES) plays a major role in determining a person's ability to obtain a healthy and health-promoting diet. People with lower incomes tend to report diets that include fewer fruits and vegetables ${ }^{(4)}$. The cost of fruits and vegetables relative to other foods is one factor that can help explain lower rates of consumption by low-income individuals ${ }^{(4-7)}$. There may be other factors, however, that are also important.

Recent attempts at understanding the complex association between individuals and dietary composition have focused on the importance of the built environment ${ }^{(8-14)}$. Neighbourhood characteristics are, themselves, a function of socio-economics and play a key role determining the availability of fruits and vegetables. Neighbourhood SES has been associated with the presence and number of supermarkets where residents are provided a broad range of fruit and vegetable options at lower costs than typically found at small groceries and specialty stores ${ }^{(13,15-17)}$.

While previous studies demonstrate the advantage of living in higher-SES neighbourhoods, they do not necessarily explain the association between individuals, their environments and dietary patterns. Low-income shoppers are quite adroit when it comes to maximizing 
their food budgets and feeding their families. They engage a range of practices that include travelling to nearby, more affluent areas and shopping in more than one store $^{(18-20)}$. In fact, most low-income shoppers do not perceive themselves as 'cut off' from supermarkets. In recent surveys, the majority of low-income participants reported easy access to a supermarket - including many who had no access to a car ${ }^{(21,22)}$.

Less is known about how characteristics of the neighbourhood food shopping environment influence fruit and vegetable purchases and dietary intake. In addition to costs and availability, low-income shoppers are also concerned with convenience, quality and selection. Convenience to these shoppers is not limited to geographic proximity, but also includes notions of temporal proximity and time savings (e.g. shopping at stores that offer products other than foods or planning routes that allow for multiple stops) ${ }^{(19)}$. Low-income shoppers also seek variety and quality; they associate quality with freshness, and they express concerns about the quality of produce in smaller stores ${ }^{(19)}$. A study of primarily lowincome African-American women in a predominantly urban setting found that selection and quality of fresh fruits and vegetables directly affected dietary intake and mediated the relationship between store characteristics (store type, size) and dietary intake ${ }^{(23)}$. Factors like quality and selection are more likely to vary from store to store than across neighbourhoods. Research conducted in the UK found only modest variation in the quality of fresh fruits and vegetables across a range of socio-economic neighbourhoods, with substantially more variation in quality among store types ${ }^{(24)}$.

The objective of the present study was to examine the relationship between residents' perceptions of their food shopping environment and dietary intake of fruits and vegetables. Data for these analyses come from the baseline assessment of a social marketing campaign conducted in six inner-city Chicago neighbourhoods, the 5-4-3-2-1 Go! Campaign ${ }^{(25)}$. The baseline survey included a set of questions related to household food shopping practices. We assessed satisfaction with three characteristics of the food shopping environment - convenience, quality and selection - and hypothesized that individuals who reported higher levels of satisfaction with the place where they typically purchased fresh fruits and vegetables would similarly report greater consumptions of fruits and vegetables. We further hypothesized that this association was independent of individuals' perceptions of the costs of fresh fruits and vegetables.

\section{Methods}

\section{Study background}

The 5-4-3-2-1 Go! Campaign was designed to alter parental behaviours within 'obesigenic' environments in low-income
Chicago communities ${ }^{(25)}$. As described in detail elsewhere, the campaign delivered an integrated set of science-based messages about nutrition and physical activity through use of small-scale, local media and grassroots efforts such as neighbourhood newspapers, radio advertisement and health fairs. Messages promoted the benefits of a healthy diet rich in fruits and vegetables and the use of community resources that support an active lifestyle ${ }^{(25)}$.

\section{Participants}

The analyses presented here are based on data from 495 respondents who participated in baseline data collection for the 5-4-3-2-1 Go! Campaign and provided complete information on all analytic variables. Based on Census tract data, we identified all households in the six study communities to construct the sampling frame. To increase the efficiency of data collection, we obtained commercially available data on household purchase decisions to develop a more targeted list of households likely to include young children. We randomly sampled from the targeted and general lists to obtain our sample. We proportionately sampled from each list as the recruitment progressed and ultimately exhausted all listed households. We used a standard recruitment script that described the overall purposes of the study and its intended use prior to admitting consenting participants into the study. To verify that parents were eligible for the study, we made initial screening calls to verify that they had children in the 3- to 7-year-old target age range for the 5-4-3-2-1 Go! Campaign and recruited those parents who met our criteria.

\section{Questionnaire design}

Respondents completed a ninety-six-item, intervieweradministered questionnaire approved as part of the overall study plan by institutional review boards at the George Washington University and Research Triangle Institute. The instrument was pretested with eighteen respondents from the targeted neighbourhoods, who were debriefed about item comprehension and not included in the subsequent evaluation. The final instrument incorporated revisions based on pretesting.

Baseline data collection was done in the winter of 2007-2008. The instrument contained a battery of questions on demographics; parent physical activity and exercise knowledge, attitudes and behaviours (KAB); parent nutrition $\mathrm{KAB}$; (parent reports of) child nutrition, physical activity and exercise $\mathrm{KAB}$; parent and child media habits; and social environmental (community resources, safety, crime) variables.

\section{Measures}

Sociodemographic characteristics

Demographic variables included race/ethnicity (white, black or Hispanic), gender, age, and participation in food 
assistance programmes (Special Supplemental Nutrition Program for Women, Infants, and Children or Supplemental Nutrition Assistance Program) as a proxy for low SES.

\section{Fruits and vegetables index}

Daily intake of fruits and vegetables was derived from a set of four items from the US Centers for Disease Control and Prevention's Behavioral Risk Factor Surveillance System (BRFSS). The BRFSS items ask respondents to provide frequency counts of: (i) green salads; (ii) servings of vegetables (excluding salad); (iii) servings of fruit; and (iv) servings of fruit juice. Respondent's answers were rendered into counts per day and summed to provide a total estimate for daily intake. In the present analysis, we dichotomized respondents into those who ate three or more fruits and vegetables daily and those who ate fewer than three fruits and vegetables daily based on the median value of the index.

\section{Fresh fruit and vegetable shopping environment}

Respondents indicated whether they primarily acquired fresh fruits and vegetables at (i) a supermarket, (ii) a farmers' market or (iii) a local co-op. For this analysis, we created a dichotomous variable that indicated either supermarket or farmers' market/co-op. In the USA, local co-ops (cooperatives) tend to be small and are retail outlets that are owned or operated by neighbourhood residents for the mutual benefit of the resident/owners. In comparison, US supermarkets are large, for-profit, commercial enterprises that sell a wide variety of foods and household goods. However, no definitions were provided to respondents as part of the data collection protocol. For fifty-two of the respondents who noted an 'other' source of fresh fruits and vegetables, the free-form response was compared with available information on retail food shops and included in one of the above three groupings.

Three items assessed respondents' perceptions of the place where they primarily acquired fresh fruits and vegetables. The first item asked respondents if they felt the place where they shop for fresh fruits and vegetables was convenient to their home. The second item asked respondents whether they were satisfied with the quality of fresh fruits and vegetables where they primarily shop. The third item asked if they were generally satisfied with the selection of fresh fruits and vegetables where they shop. For each item, a 4-point response set ranged from 'strongly agree' to 'strongly disagree'; responses 'no opinion' and 'don't know' were converted to missing and excluded from the analysis.

\section{Cost of fruits and vegetables}

One item asked respondents to what extent they agreed with the statement, 'Fruits and vegetables are too expensive'. A 4-point response set ranged from 'strongly agree' to 'strongly disagree'; responses 'no opinion' and 'don't know' were converted to missing and excluded from the analysis.

\section{Food shopping habits}

Two variables examined characteristics related to shopping. First, respondents identified the household's primary food shopper as themselves, their spouse or some other adult. For analyses, these responses were dichotomized to 'self' and 'other'. Second, respondents indicated the number times per month they shopped for food for the household.

\section{Data analysis}

Prior to conducting regression analyses, a confirmatory principal factor analysis examined the set of survey items assessing satisfaction with the food shopping environment. A factor loading criterion of 0.50 was used to ascertain whether a perceived satisfaction scale could be created from a series of questions related to convenience, quality and selection when shopping for fruits and vegetables ${ }^{(26)}$. All three variables met the factor loading criterion and the Cronbach $\alpha$ coefficient of 0.78 met minimum threshold standards $(>0 \cdot 70)$ confirming a high level of inter-item consistency. The three items in the scale were summed and averaged to retain the range of the original items.

Multivariable logistic regression was conducted by performing the regression of the dichotomized fruit and vegetable index $v$. the perceived satisfaction index, variables related to the respondents' shopping practices and the food shopping environment. The regression model also controlled for sociodemographic characteristics. Analyses were conducted using the STATA statistical software package version 11 (2009; StatCorp LP, College Station, TX, USA).

\section{Results}

Respondents' descriptive statistics are shown in Table 1. The sample included 495 of the 526 baseline respondents (94\%); this group provided complete data on all analytic variables. The sample was primarily female $(78.8 \%)$, with a mean age of $35 \cdot 7$ (range $18-75$ ) years. Most respondents were African American $(44.5 \%)$ or Hispanic (43.0\%). Based on participation in federal food assistance programmes, $48 \cdot 3 \%$ of the population could be characterized as low income. Table 1 also provides information on the sample's fresh fruit and vegetable intake and shopping habits. Self-reported intake of fruits and vegetables ranged from 0 to 18, with a mean of $5 \cdot 1$ fruits and vegetables daily. In total, $85 \cdot 5 \%$ of our sample indicated they ate three or more fruits and vegetables daily. Overall, respondents indicated that they participated in food shopping 4.9 times per month.

As shown in Table 2, variables assessing the food shopping environment were significantly related to dietary intake of fruits and vegetables. Respondents who reported higher levels of satisfaction were more likely to eat three or more servings of fruits and vegetables daily. Compared with respondents who indicated they were not happy with 
their fresh fruit and vegetable shopping options, those who agreed that they had convenient access to quality and selection were $2 \cdot 13$ times as likely to eat three or more servings while those who strongly agreed were $4 \cdot 42$ times as likely to eat three or more servings of fruits and vegetables daily. Additionally, those shopping at a local co-op or a farmers' market rather than a supermarket were 2.77 times more likely to report eating three or more servings of fruits and vegetables daily.

Table 1 Demographic characteristics of respondents: community sample drawn from six low-income, primarily minority neighbourhoods, Chicago, IL, USA, winter of 2007-2008

\begin{tabular}{lcc}
\hline Variable & Frequency* & $\begin{array}{c}\text { Percentage } \\
\text { of total }\end{array}$ \\
\hline Sex & 515 & \\
Male & 109 & $21 \cdot 17$ \\
Female & 406 & $78 \cdot 83$ \\
Race/ethnicity & 526 & \\
Black & 234 & $44 \cdot 49$ \\
Hispanic & 226 & $42 \cdot 97$ \\
White & 66 & $12 \cdot 55$ \\
Age (years) & 522 & \\
18-24 & 85 & $16 \cdot 28$ \\
25-34 & 191 & $36 \cdot 59$ \\
35-44 & 133 & $25 \cdot 48$ \\
$\geq 45$ & 113 & $21 \cdot 65$ \\
Participates in WIC/SNAPt & 251 & $48 \cdot 27$ \\
Reported fruits and vegetables/ & 525 & \\
d & & \\
0-2 & 76 & $14 \cdot 48$ \\
$\geq 3$ & 449 & $85 \cdot 52$ \\
Market type & 511 & \\
Supermarket & 268 & $52 \cdot 45$ \\
Farmers' market/local co-op & 243 & $47 \cdot 55$ \\
\hline
\end{tabular}

WIC, Special Supplemental Nutrition Program for Women, Infants, and Children; SNAP, Supplemental Nutrition Assistance Program.

*Total sample included 526 participants; minor variations due to missing items. +WIC and SNAP are US federal food assistance programmes for low-income individuals and families.
Our data also indicated that respondents making frequent shopping trips were more likely to report higher fruit and vegetable consumption. Compared with those who made four shopping trips per month (i.e. weekly), those who made six shopping trips per month were $2 \cdot 10$ times as likely to report higher fruit and vegetable consumption. Our findings did not, however, support the hypothesized independent association between perceived cost and dietary intake.

\section{Discussion}

Despite being a primarily minority and low-income inner-city sample, the majority of respondents reported reasonably high levels of fruit and vegetable consumption compared with national averages ${ }^{(4)}$. Additionally, our sample seemed to have very good access to supermarkets and farmers' markets. This observation concurs with Rose and Richards' finding that few low-income individuals lack access to supermarkets ${ }^{(21)}$.

Our data support the hypothesis that perceived satisfaction with the food shopping environment is associated with fruit and vegetable consumption. Among this urban, primarily minority sample, those who felt that the places they purchased fresh fruits and vegetables were convenient and provided higher levels of quality and selection were more likely to eat three or more servings of fruit and vegetables daily. Compared with respondents who were not satisfied, those who agreed that the places they purchased fruits and vegetables provided quality, selection and convenience were more than two times as likely to eat three or more servings of fruits and vegetables daily, while those who strongly agreed with these statements were more than four times more likely to eat three or more

Table 2 Variables predicting fruit and vegetable intake: community sample drawn from six low-income, primarily minority neighbourhoods, Chicago, IL, USA, winter of 2007-2008

\begin{tabular}{|c|c|c|c|c|}
\hline Variable & OR & $\mathrm{Cl}$ & SE & $P$ value \\
\hline Perceived satisfaction scale & $2 \cdot 13$ & $1 \cdot 16,3 \cdot 93$ & 0.6658 & 0.015 \\
\hline Frequency of shopping & $1 \cdot 45$ & $1 \cdot 06,2 \cdot 00$ & 0.2342 & $0 \cdot 019$ \\
\hline \multicolumn{5}{|l|}{ Market type } \\
\hline Farmers' market/local co-op & $2 \cdot 77$ & $1 \cdot 55,4 \cdot 96$ & $0 \cdot 8230$ & 0.001 \\
\hline Supermarket (ref.) & $1 \cdot 00$ & - & - & - \\
\hline Fruits and vegetables too expensive & $1 \cdot 36$ & $0.93,1.98$ & $0 \cdot 2607$ & $0 \cdot 107$ \\
\hline Primary shopper? & $1 \cdot 14$ & $0 \cdot 56,2 \cdot 31$ & $0 \cdot 4105$ & $0 \cdot 717$ \\
\hline \multicolumn{5}{|l|}{ Sex } \\
\hline Male & $1 \cdot 79$ & $0.80,3.99$ & 0.7323 & $0 \cdot 154$ \\
\hline Female (ref.) & $1 \cdot 00$ & - & - & - \\
\hline \multicolumn{5}{|l|}{ Race/ethnicity } \\
\hline Black & 1.06 & $0.33,3 \cdot 38$ & $0 \cdot 6276$ & 0.926 \\
\hline Hispanic & $0 \cdot 79$ & $0 \cdot 18,1 \cdot 50$ & 0.4451 & 0.679 \\
\hline White (ref.) & $1 \cdot 00$ & - & - & - \\
\hline Age (quartiles $\left.{ }^{\star}\right)$ & $1 \cdot 01$ & $0 \cdot 76,1 \cdot 32$ & $0 \cdot 41$ & 0.96 \\
\hline Participates in WIC/SNAPt & 1.43 & $0 \cdot 81,2 \cdot 54$ & 0.4187 & $0 \cdot 219$ \\
\hline
\end{tabular}

ref., reference category; WIC, Special Supplemental Nutrition Program for Women, Infants, and Children; SNAP, Supplemental Nutrition Assistance Program.

${ }^{*}$ Quartiles for age: 18-24 years (ref.), 25-34 years, 35-44 years and $\geq 45$ years.

+WIC and SNAP are US federal food assistance programmes for low-income individuals and families. 
servings daily. These findings confirm those reported by Zenk and colleagues ${ }^{(23)}$. Their study, also conducted among an inner-city low-income population, found that perceived quality and selection influenced dietary intake of fruits and vegetables independent of perceived cost.

Additionally, our data indicate that respondents who shopped at farmers' markets and/or co-ops were 2.77 times more likely to eat three or more servings of fruits and vegetables daily than were respondents who shopped at supermarkets. These associations are independent of sociodemographic characteristics and whether or not respondents viewed fruits and vegetables as too expensive. In fact, perceived cost was not associated with dietary intake among this predominantly minority and low-income audience. Respondents who agreed that cost was a barrier to eating fruits and vegetables did not report lower dietary intake than respondents who disagreed that cost was a barrier.

The present study has several limitations that must be considered when interpreting these findings. First, our data are cross-sectional and observational. We cannot claim, for example, that greater perceived satisfaction with the food shopping environment would lead to greater increases in fruit and vegetable consumption. It is equally probable that individuals with a preference for diets rich in fruits and vegetables seek out stores with better quality and selection. Similarly, the association between shopping at farmers' markets/local co-ops and dietary intake may reflect the personal preferences of individuals who seek out these specialty establishments because they perceive them as providing greater value.

Second, our study is a secondary analysis and we are limited by the items available in the survey. For example, we do not have information on sociodemographic variables such as educational attainment or household income. These variables have been shown to be associated with fruit and vegetable consumption in previous research $^{(6,23,27,28)}$. The present survey does not allow us to exclude respondents who do not participate in food shopping. Instead, the survey asks who does most of the household food shopping with response options including self, spouse or other adult. Although the primary shopper may have more experience with the food shopping environment, it is quite common today to find that adults share household food shopping responsibilities and the experiences of occasional food shoppers should not be discounted. Accordingly, we chose to control for, rather than exclude, respondents based on this variable. The survey also did not include questions assessing the availability of a car or other forms of transportation. Individuals with more access to transportation would similarly have greater choice of food shopping venues and may have opted to travel further to seek stores that offer selection and quality. It is easy to conceive that individuals with a car would have a different perception of 'convenience' than those who are without.
Other variables may lack sufficient differentiation. Our variable assessing the type of food store was limited to three options - supermarket, co-op and farmers' market which may not be sufficient important differences in the shopping experience in an environment that includes neighbourhood grocers and corner stores. Future studies should consider the complexity of the food shopping environment. Providing respondents with more options including corner stores and local groceries - and clearly defining retail outlets to help respondents distinguish among these venues may promote a better understanding of how perceived quality and store type influence affect fruit and vegetable intake.

Finally, it is important to note that the variables measuring dietary intake of fruits and vegetables assess all fruit and vegetable consumption including fresh, frozen, canned and dried forms, while our measures of the food shopping environment ask specifically about the place where respondents typically purchase fresh fruits and vegetables. The place where respondents in our study purchase fresh fruits and vegetables may not be the place they purchase all forms of fruits and vegetables. In fact, previous studies have found that low-income shoppers frequently shop at more than one venue ${ }^{(18)}$.

Despite these limitations, our study extends the growing body of literature that highlights the importance of personal, subjective assessments of the food shopping environment ${ }^{(19,23,24,29)}$. Our analysis examines the role that perceptions of the quality, selection and convenience may play in promoting increased consumption of fruits and vegetables. Our findings suggest that these perceptions matter. Low-income shoppers do not simply make dietary choices based on cost and availability; they also consider less tangible aspects of the food shopping environment that relate to quality and satisfaction.

There is growing support in the public health community for policy, system and environmental changes that promote healthy eating ${ }^{(30-32)}$. The goal of policy, system and environmental change is to alter the built environment by decreasing costs and barriers associated with healthy choices. Those pursing policy, system and environmental change have attempted to increase fresh fruit and vegetable offerings in corners stores ${ }^{(31)}$ and to increase the number of and access to farmers' markets ${ }^{(33,34)}$. Providing access is an important step. However, interventionists would do well to think past simple structural obstacles and consider the relational contexts of persons and environments ${ }^{(35)}$. Our study offers a cautionary note to those who promote policy, system and environmental change. It suggests that lowering barriers without due attention to the concerns of the target populations is likely to be met with resistance; alternatively, working with local retailers to improve shopping convenience and provide a good selection of quality food items may influence consumers' overall fruit and vegetable intake independent of price and availability. 


\section{Acknowledgements}

The research was funded by a grant from the PepsiCo Foundation and Charitable Contributions. The authors have no conflicts of interest. W.D.E. and J.L.B. contributed to the development of the 5-4-3-2-1 Go! Campaign. All authors shared equally in the conceptualization of the analyses reported herein. J.L.B. and J.S. implemented the analyses. All authors reviewed the analyses and contributed to the development and editing of the manuscript.

\section{References}

1. US Department of Agriculture \& US Department of Health and Human Services (2010) Dietary Guidelines for Americans, 2010, 7th ed. Washington, DC: US Government Printing Office.

2. Drewnowski A (2004) Obesity and the food environment. Am J Prev Med 27, 154-162.

3. Van Duyn MA \& Pivonka E (2000) Overview of the health benefits of fruit and vegetable consumption for the dietetics professionals: selected literature. J Am Diet Assoc 100, 1511-1521.

4. Centers for Disease Control and Prevention (2010) Statespecific trends in fruit and vegetable consumption among adults - United States, 2000-2009. MMWR Morb Mortal Wkly Rep 59, 1125-1131.

5. Cassady D, Jetter KM \& Culp J (2007) Is price a barrier to eating more fruits and vegetables for low-income families? J Am Diet Assoc 107, 1909-1915.

6. Ard JD, Fitzpatrick S, Desmond RA et al. (2007) The impact of cost on the availability of fruits and vegetables in the homes of schoolchildren in Birmingham, Alabama. Am J Public Health 97, 367-372.

7. Drewnowski A \& Darmon N (2005) Food choices and diet costs: an economic analysis. J Nutr 135, 900-904.

8. Booth KM, Pinkston MM \& Poston WSC (2005) Obesity and the built environment. J Am Diet Assoc 105, S110-S117.

9. Hill JO, Wyatt HR, Reed GW et al. (2003) Obesity and the environment: where do we go from here? Science $\mathbf{2 9 9}$, 853-855.

10. Barrera Jr M, Strycker LA, MacKinnon DP et al. (2008) Social-ecological resources as mediators of two-year diet and physical activity outcomes in type 2 diabetes patients. Health Psychol 27, S118-S125.

11. Burdette HL \& Whitaker RC (2004) Neighborhood playgrounds, fast food restaurants, and crime: relationships to overweight in low-income preschool children. Prev Med $\mathbf{5 7}, 57-63$.

12. Veenstra G, Luginaah I, Wakefield S et al. (2005) Who you know, where you live: social capital, neighborhood and health. Soc Sci Med 60, 2799-2818.

13. Morland K, Wing S, Roux AD et al. (2002) Neighborhood characteristics associated with the location of food stores and food service places. Am J Prev Med 22, 23-29.

14. Lopez R \& Hynes HP (2006) Obesity, physical activity, and the urban environment: public health research needs. Environ Health 5, e25.

15. Latham J \& Moffat T (2007) Determinants of variation in food cost and availability in two socioeconomically contrasting neighbourhoods of Hamilton, Ontario, Canada. Health Place 13, 273-287.

16. Morland K \& Filomena S (2007) Disparities in the availability of fruits and vegetables between racially segregated urban neighborhoods. Public Health Nutr 12, 1481-1489.
17. Powell LM, Slater S, Mirtcheva D et al. (2007) Food store availability and neighborhood characteristics in the United States. Prev Med 44, 189-195.

18. Hersey J, Anliker J, Miller C et al. (2001) Food shopping practices are associated with dietary quality in low-income households. J Nutr Educ 33, Suppl. 1, S16-S26.

19. Webber CB, Sobal J \& Dollahite JS (2010) Shopping for fruits and vegetables. Food and retail qualities of importance to low-income households at the grocery store. Appetite $\mathbf{5 4}$, 297-303.

20. Inagami S, Cohen DA, Finch BK et al. (2006) You are where you shop: grocery store locations, weight, and neighborhoods. Am J Prev Med 31, 10-17.

21. Rose D \& Richards R (2004) Food store access and household fruit and vegetable use among participants in the US food stamp program. Public Health Nutr 7, 1081-1088.

22. Dibsdall LA, Lambert N, Bobbin RF et al. (2003) Lowincome consumers' attitudes and behaviour towards access, availabilty and motivation to eat fruit and vegetables. Public Health Nutr 6, 159-168.

23. Zenk SN, Schulz AJ, Hollis-Neely T et al. (2005) Fruit and vegetable intake in African Americans: income and store characteristics. Am J Prev Med 29, 1-9.

24. Cummins S, Smith DM, Taylor M et al. (2009) Variations in fresh fruit and vegetable quality by store type, urban-rural setting and neighbourhood deprivation in Scotland. Public Health Nutr 12, 2044-2050.

25. Evans WD, Necheles J, Longjohn M et al. (2007) The 5-4-3-2-1 Go! intervention: social marketing strategies for nutrition. J Nutr Educ Behav 39, S55-S59.

26. Comrey HB \& Lee AL (1992) A First Course in Factor Analysis. HIllsdale, NJ: Lawrence Erlbaum Associates, Inc.

27. Ball K, Crawford D \& Mishra G (2006) Socio-economic inequities in women's fruit and vegetable intakes: a multilevel study of individual, social, and environmental mediators. Public Health Nutr 9, 623-630.

28. Shohaimi S, Welch A, Bingham S et al. (2004) Residential area deprivation predicts fruit and vegetable consumption independently of individual educational level and occupational social class: a cross sectional population study in the Norfolk cohort of the European Prospective Investigation into Cancer (EPIC-Norfolk). J Epidemiol Community Health 58, 686-691.

29. Freedman DA \& Bell BA (2009) Access to healthful foods among an urban food insecure population: perceptions versus reality. J Urban Health 86, 825-837.

30. Sacks G, Swinburn B \& Lawrence M (2009) Obesity policy action framework and analysis grids for a comprehensive policy approach to reducing obesity. Obes Rev 10, 76-86.

31. Gregson J, Foerster SB, Orr R et al. (2001) System, environmental, and policy changes: using the socialecological model as a framework for evaluating nutrition education and social marketing programs with low-income audiences. J Nutr Educ 33, Suppl. 1, S4-S15.

32. Glanz K \& Yaroch AL (2004) Strategies for increasing fruit and vegetable intake in grocery stores and communities: policy, pricing, and environmental change. Prev Med 39, Suppl. 2, S75-S80.

33. Wasserman W, Tropp D, Lakins V et al. (2010) Supplemental Nutrition Assistance Program (SNAP) at Farmers Market: A How-to Handbook. Washington, DC: USDA, Agricultural Marketing Service.

34. Briggs S, Fisher A, Lott M et al. (2010) Real Food, Real Choice: Connecting SNAP Recipients with Farmers Markets. Portland, OR: Community Food Security Coaliation.

35. Cummins S, Curtis S, Diez-Roux AV et al. (2007) Understanding and representing place in health research: a relational approach. Soc Sci Med 65, 1825-1838. 